\title{
Pembelajaran Berasaskan Permainan Dalam Mata Pelajaran Sejarah Menggunakan Teknik Mnemonik
}

\author{
Game Based Learning in History Subjects Using Mnemonic Techniques
}

\author{
Nurul Syadiyah binti Khairuddin', Ramlah binti Mailok ${ }^{2}$ \\ ${ }^{1}$ Universiti Pendidikan Sultan Idris; nsyadiyahkhairuddin@gmail.com \\ ${ }^{2}$ Universiti Pendidikan Sultan Idris; mramlah@fskik.upsi.edu.my
}

DOI: https://doi.org/10.37134/jictie.vol7.1.2.2020

\begin{abstract}
Abstrak
Bagi mewujudkan minat pelajar dalam pembelajaran, pelbagai inisiatif yang dilakukan oleh guru untuk menjadikan suasana proses pengajaran dan pembelajaran menjadi lebih seronok. Kertas konsep ini membincangkan tentang isu Pembelajaran Berasaskan Permainan (PBP), teknik mnemonik, mata pelajaran Sejarah dan teori-teori yang berkaitan. Antara isu yang diketengahkan adalah impak positif penggunaan PBP dalam pembelajaran dan kelebihan teknik mnemonik dalam mengingat pembelajaran. Kajian literatur menunjukkan PBP dapat mewujudkan suasana bilik darjah yang menyeronokkan dan membantu pelajar lebih bermotivasi dan aktif dalam pembelajaran seperti perbendaharaan kata, Matematik dan hukum Newton. Namun, kajian ke atas PBP bagi mata pelajaran Sejarah adalah kurang. Justeru itu, kertas konsep ini membincangkan tentang kerangka konsep bagi permainan digital yang melibatkan mata pelajaran Sejarah menggunakan teknik mnemonik.
\end{abstract}

Kata Kunci: pembelajaran berasaskan permainan, teknik mnemonik, mata pelajaran Sejarah.

\begin{abstract}
In order to create students' interest in learning, various initiatives by teachers to make the teaching and learning process more fun. This concept paper discusses the issue of Game-Based Learning (GBL), mnemonic techniques, History subjects and related theories. Among the issues raised is the positive impact of the use of GBL in learning and the advantages of mnemonic techniques in remembering learning. Literature research shows GBL can create a fun classroom atmosphere and help students be more motivated and active in learning like Newton's vocabulary, mathematics and law. However, studies on GBL for History subjects are less. Hence, this concept paper discusses the conceptual framework for digital games involving History subjects using a mnemonic technique.
\end{abstract}

Keywords: game-based learning, mnemonic technique, History subject. 


\section{PENGENALAN}

Apabila disebut sahaja abad ke-21, sudah tentu sinonim dengan teknologi-teknologi canggih dan moden yang dibangunkan oleh manusia. Abad ke-21 merupakan satu zaman yang melibatkan persaingan dari seluruh pelusuk dunia untuk mencipta dan membangunkan alat-alat yang moden dan canggih untuk kegunaan dalam segala bidang sama ada bidang perniagaan, perubatan, pengangkutan dan tidak ketinggalan juga dalam bidang pendidikan. Malaysia juga tidak terkecuali dalam mengejar arus permodenan yang semakin canggih agar tidak ketinggalan dengan kemajuan teknologi-teknologi moden pada masa kini yang saban hari semakin baru dan up to date. Di Malaysia, bidang pendidikan juga menjurus ke arah penggunaan komputer serta pembelajaran berasaskan permainan di dalam bilik darjah.

Ini seiring dengan Pelan Pembangunan Pendidikan Negara 2013-2025 yang menyatakan penggunaan komputer merupakan salah satu ciri-ciri pengajaran dan pembelajaran abad ke 21. Pengajaran dan pembelajaran pada abad ke 21 lebih cenderung kepada penggunaan alat bahan bantu mengajar (ABBM) yang dibina menggunakan platform seperti aplikasi mobil, koswer serta pembelajaran berasaskan permainan. Ini juga merupakan satu cabaran bagi para guru untuk membimbing para pelajar supaya berfikiran kreatif dan kritis.

\section{TINJAUAN LITERATUR}

\section{Pembelajaran Berasaskan Permainan dan Teori Berkaitan}

Menurut Weng dan Kamisah (2018), terdapat pelbagai definisi yang menyatakan maksud Pembelajaran Berasaskan Permainan (PBP) dan tiada definisi yang khusus untuk PBP. PBP digunakan sebagai satu platform untuk meransang dan menggalakkan pelajar agar lebih aktif dalam mengambil bahagian ketika proses pembelajaran berlaku serta menjadikan proses pembelajaran lebih menyeronokkan (Rula, Fatma \& Mazin, 2016). PBP permainan merupakan gabungan permainan dan pembelajaran agar proses pengajaran dan pembelajaran lebih menyeronokkan berbanding proses pengajaran dan pembelajaran tradisional yang membosankan (Rula et al., 2016). Sahar (2016) turut menyatakan permainan dapat mengekalkan momentum pelajar dalam usaha dan minat ketika proses pengajaran dan pembelajaran berlangsung serta menjadikan suasana dalam bilik darjah lebih menyeronokkan dan menghiburkan. Menurut Weng dan Kamisah (2018), terdapat dua jenis permainan iaitu permainan digital dan bukan digital.

Menurut Bradley (2016) yang menyatakan PBP yang berbentuk permainan digital atau bukan digital sebagai tujuan untuk mencapai satu atau beberapa objektif pembelajaran. Menurut Nurfazliah, Megat, Shaharudin dan Jamalludin (2018), sudah diakui bahawa permainan digital dapat menghasilkan kemahiran pelajar yang bersesuaian dengan abad ke 21. Begitu juga dengan Bradley (2016) yang turut menyatakan bahawa permainan digital lebih menjadi pilihan dalam meningkatkan pendidikan 
kurikulum untuk mengekalkan fokus dan meningkatkan pengetahuan sedia ada. Melihat kepada Pelan Pembangunan Pendidikan Malaysia 2013-2025, sasaran pendidikan adalah untuk melahirkan individu yang berilmu pengetahuan dan mempunyai kemahiran supaya Berjaya dalam kehidupan (Weng \& Kamisah, 2018). Menurut Nurfazliah et al. (2018), PBP atau permainan digital dalam pembelajaran merupakan satu teknik atau kaedah yang bersesuaian untuk membantu meningkatkan kemahiran dalam menyelesaikan masalah.

Menurut Kementerian Pendidikan Malaysia (2013), setiap pelajar perlu memiliki kemahiran membaca, menulis, mengira dan kemahiran berfikir aras tinggi (Weng \& Kamisah, 2018). Selain itu, Weng dan Kamisah (2018) turut menyatakan penilaian bagi pembelajaran pelajar tidak perlu fokus kepada peperiksaan sahaja malah perlu menitikberatkan kemahiran abad ke 21 seperti kemahiran maklumat, teknologi, kemahiran hidup dan kerjaya. Hal ini dapat dibantu dengan menggunakan pendekatan PBP yang dapat meningkatkan kemahiran abad ke 21 yang menyediakan persekitaran kepada pelajar untuk mengaplikasikan kemahiran-kemahiran semasa perbincangan pelajar, menyelesaikan masalah dan memperoleh idea dalam pembelajaran (Weng \& Kamisah, 2018). Hal ini menunjukkan PBP satu pendekatan yang menggunakan permainan untuk pendidikan (Weng \& Kamisah, 2018).

Kajian-kajian lepas menunjukkan teori Piaget yang digunakan oleh pengkaji-pengkaji dalam menjalankan kajian yang berkaitan dengan PBP (Aliza \& Zamri, 2015; Azita \& Patrick, 2015; Aliza \& Zamri, 2016). Piaget (1951) menyatakan bahawa kanak-kanak belajar secara aktif dengan menggunakan objek-objek yang ada di sekeliling semasa bermain dan berinteraksi dengan persekitaran (Aliza \& Zamri, 2015; Fatimah, 2015). Teori Piaget menyatakan tentang perkembangan kognitif berlaku dalam empat tahap iaitu sensorimotor, tahap pra-operasional, operasional konkrit dan operasional formal (Fatimah, 2015). Teori Piaget sangat jelas dengan perkembangan kognitif iaitu manusia mempunyai tahap perkembangan tertentu dengan melihat kemampuan berfikir manusia (Fatimah, 2015). Menurut Piaget juga pengetahuan dibentuk melalui dua bentuk iaitu asimilasi dan akomodasi (Tri, 2015). Asimilasi kognitif berlaku melalui peristiwa yang sama iaitu penyesuaian diri dengan keadaan dalam lingkungannya manakala akomodasi pula penyesuaian diri dengan keadaan di luar lingkungannya (Tri, 2015).

Permainan sangat berkesan dan bukan sahaja membantu pelajar dalam mempelajari perbendaharaan kata malah memberi motivasi kepada pelajar untuk melinatkan diri dalam persaingan yang sihat dan mewujudkan persekitaran pembelajaran koperatif (Ali \& Ilham, 2015). Sahar (2016) ada menyatakan permainan adalah satu kaedah pembelajaran yang mengelakkan suasana bosan dalam bilik darjah. 


\section{TEKNIK MNEMONIK DALAM PEMBELAJARAN MATA PELAJARAN SEJARAH}

Perkataan mnemonik berasal daripada bahasa Yunani iaitu mnemosyne yang merujuk kepada dewi Yunani kuno yang wujud daripada ingatan (Pal, 2014; Parima, Siros \& Ali, 2018; Bih \& Nurul, 2019). Teknik mnemonik merupakan satu teknik yang efektif dalam meningkatkan ingatan individu (Bih dan Nurul, 2019). Teknik mnemonik adalah satu alat bantu mental individu untuk membantu individu mengingati maklumat seperti nama, nombor, formula, perkataan baru dan tarikh sejarah (Parima et al., 2018). Menurut Bih dan Nurul (2019), teknik mnemonik menjadikan proses mengingat menjadi lebih mudah dengan menggunakan prinsip penyatuan iaitu mengaitkan maklumat yang perlu diingat dengan maklumat yang lebih mudah untuk diingat. Jenis teknik mnemonik yang digunakan adalah pelbagai bergantung kepada cara seseorang mengingat sesuatu maklumat kerana setiap individu mempunyai cara mengingat yang berbeza (Bih \& Nurul, 2019).

Namun, terdapat beberapa teknik mnemonik yang selalu digunakan seperti kata kunci, loci, akronim dan pegword (Mailis, Rahmah \& Bansu, 2016; Dicky, Ying, Yulyani \& Kelly, 2017). Kata kunci berfungsi dengan cara mengaitkan dan membunyikan perkataan yang baru kepada perkataan yang sudah diketahui sebelum ini (Parima et al., 2018; Ying et al., 2016). Terdapat banyak kajian yang menunjukkan kata kunci berkesan dalam pembelajaran yang melibatkan hafalan pembelajaran yang banyak (Marjan \& Farzin, 2015; Ali \& Mohammad, 2016; Ana \& Ramin, 2014; Mohammad \& Dina, 2016). Loci pula membantu untuk mengingat maklumat dalam senarai perkataan dan perbendaharaan kata dengan menggunakan imej (Dicky et al., 2017; Adam, 2015). Menurut Touran dan Sepideh (2015) yang melakukan kajian dengan membandingkan pembelajaran secara latihan dengan pembelajaran menggunakan loci, terdapat perbezaan yang ketara apabila pelajar yang belajar dengan menggunakan loci lebih mudah untuk mengingat semula perkataan daripada pelajar yang belajar dengan cara latihan sahaja. Menurut Mohammad dan Dina (2016), teknik mnemonik membantu pelajar untuk mengingat perbendaharaan kata yang banyak dengan mudah.

Teknik mnemonik banyak digunakan untuk membantu pelajar dalam mengingat pembelajaran yang banyak (Marjan \& Farzin, 2015; Ali \& Mohammad, 2016; Ana \& Ramin, 2014; Mohammad \& Dina, 2016) seperti perbendaharaan kata, Sains, Matematik dan Sejarah. Terdapat kajian yang menunjukkan teknik mnemonik membantu pelajar dalam menyelesaikan masalah dalam mata pelajaran Matematik (Mojeed \& Ezekiel, 2014; Mailis et al., 2016). Menurut Onur (2014), teknik mnemonik membantu pelajar untuk mengingat perbendaharaan kata yang banyak. Selain itu, teknik mnemonik turut membantu pelajar untuk mengingat perbendaharaan kata bahasa Cina (Ying, Dicky \& Yulyani, 2016). Mata pelajaran Sejarah juga merupakan mata pelajaran yang boleh menggunakan teknik menmonik untuk mengingat tarikh-tarikh serta nama-nama yang banyak.

Kajian-kajian lepas banyak menggunakan teknik mnemonik bagi pembelajaran yang banyak seperti perbendaharaan kata yang banyak, perbendaharaan kata bahasa cina dan Matematik (Mojeed \& Ezekiel, 2014; Mailis et al., 2016; Ying, Dicky \& Yulyani, 2016; Onur \& Ahmet 2014). Namun, masih kurang kajian yang menggunakan teknik mnemonik bagi mata pelajaran Sejarah. 


\section{PEMBELAJARAN BERASASKAN PERMAINAN DALAM PEMBELAJARAN MATA PELAJARAN SEJARAH DAN KERANGKA KONSEP}

PBP menggunakan permainan digital bukan lagi sesuatu yang baharu (Nurfazliah et al., 2018). PBP sangat popular dan sangat mendapat perhatian untuk kegunaan bagi pembelajaran perbendaharaan kata (Ali \& Elham, 2015). Menurut Mazeyanti, Alan dan Suziah (2014), istilah PBP mencapai 162 juta carian Google dan 2.37 juta dokumen yang merupakan kertas akademik di carian Google Scholar dan ini menunjukkan bahawa PBP mendapat perhatian daripada para penyelidik serta para guru.

Kelebihan PBP digital dapat menjadikan pelajar lebih kreatif, fokus, lebih minat dalam proses pembelajaran dan menggalakkan kolaboratif bersama rakan melalui penyelesaian masalah (Khairuddin, 2015). Proses pembelajaran juga memerlukan individu untuk mengingat setiap maklumat yang dipelajari. Menurut Siti dan Faridah (2017), PBP membantu pelajar dalam mengenal pasti elemen kritikal dalam mempelajari hukum Newton. Penggunaan permainan dalam pengajaran dan pembelajaran membantu pelajar untuk belajar perbendaharaan kata dengan lebih efektif (Sahar, 2016). Selain itu, menurut Muchamad dan Medika (2016), permainan turut membantu pelajar untuk lebih memahami Matematik.

Namun begitu, PBP masih kurang bagi mata pelajaran Sejarah. Oleh itu, objektif yang ingin dicapai di dalam kertas konsep ini adalah untuk membina satu kerangka konsep yang akan digunakan dalam pembinaan sebuah PBP yang bakal digunakan oleh para guru sebagai bahan bantu mengajar bagi menjadikan pembelajaran lebih menyeronokkan dan membantu para pelajar lebih memahami pembelajaran yang dipelajari.

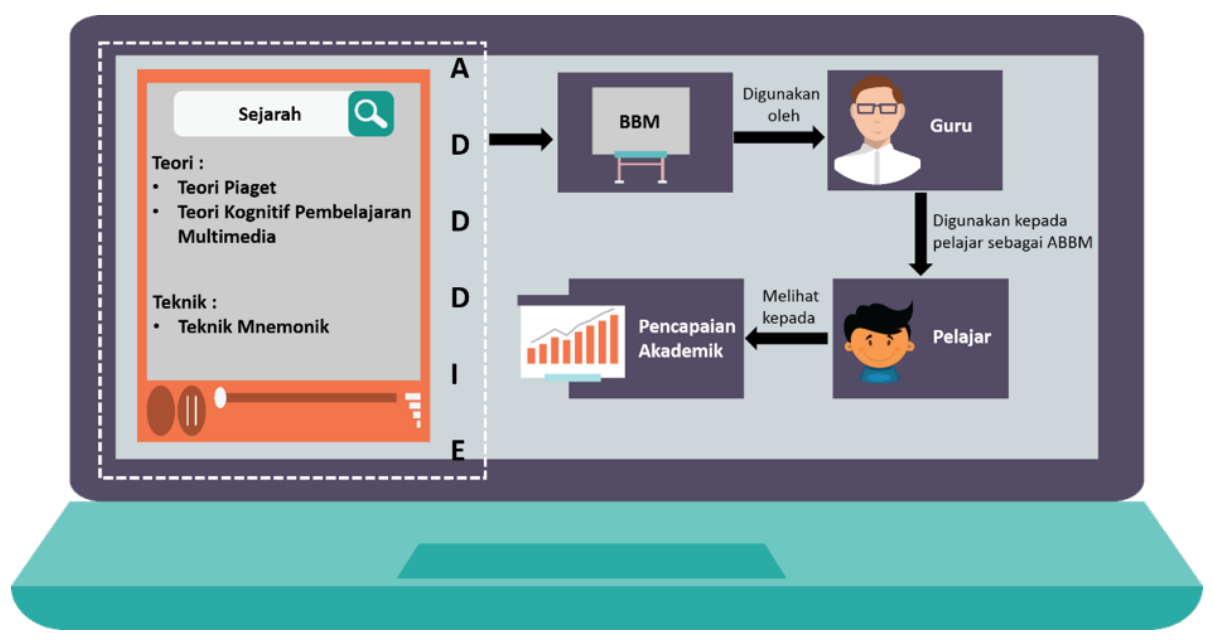

Rajah 1: Kerangka konseptual Pembelajaran Berasaskan Permainan dalam mata pelajaran Sejarah menggunakan teknik mnemonik 
Kerangka konseptual dalam kajian ini sebagai panduan dan cadangan kepada para guru untuk membina satu bahan bantu mengajar yang dapat membantu dalam pencapaian akademik para pelajar. Pembelajaran bermakna merupakan satu proses yang dilakukan oleh pelajar dalam mengaitkan konsep yang baru dengan pengetahuan sedia ada dalam kognitif pelajar (Weng \& Kamisah, 2018). Antara teori yang diketengahkan dalam kertas konsep ini ialah teori Piaget dan teori kognitif pembelajaran multimedia (Mayer, 2009). Teknik mnemonik merupakan teknik yang dimasukkan dalam PBP untuk mata pelajaran Sejarah bagi membantu pelajar supaya mudah mengingat pembelajaran Sejarah. Model ADDIE merupakan model yang digunakan oleh para guru dalam reka bentuk pengajaran di seluruh pelusuk dunia yang mempunyai garis panduan bagi membantu para guru untuk membina bahan bantu mengajar yang berkesan dalam lima fasa iaitu analisis, reka bentuk, pembangunan, pelaksanaan dan penilaian (Razali \& Shahbodin 2015). Kerangka konseptual ini adalah untuk memberi bayangan serta idea kepada para guru untuk membina bahan bantu mengajar sebagai kegunaan para guru untuk mengajar para pelajar agar dapat meningkatan pencapaian akademik pelajar dalam mata pelajaran Sejarah seperti dalam Rajah 1.

\section{KESIMPULAN}

Kajian-kajian lepas menunjukkan pembelajaran yang melibatkan permainan dapat membantu pembelajaran menjadi lebih seronok. Permainan kini bukan lagi sekadar hiburan malah dapat memupuk motivasi pelajar supaya lebih bersemangat dalam proses pengajaran dan pembelajaran. Kerangka konsep yang dicadangkan diharap dapat memberikan satu idea dan inisiatif baru kepada para guru untuk menjadikannya sebagai satu bahan bantu mengajar dalam meningkatkan motivasi dan pencapaian akademik pelajar.

\section{RUJUKAN}

Abdul Jabbar, A.I., \& Felicia, P. (2015). Gameplay Engagement and Learning In Game-Based Learning: A Systematic Review. Review of Educational Research, 85(4), 740-779.

Ah-Nam, L., \& Osman, K. (2017). Developing 21st Century Skills Through A Constructivist-Constructionist Learning Environment. K-12 STEM Education, 3(2), 205-216.

Ahour, T., \& Berenji, S. (2015). A Comparative Study Of Rehearsal And Loci Methods In Learning Vocabulary In EFL Context. Theory and Practice in Language Studies, 5(7), 1451-1457.

Akinsola, M.K., \& Odeyemi, E.O. (2014). Effects of Mnemonic and Prior Knowledge Instructional Strategies on Students Achievement in Mathematics. International Journal of Education and Research, 2(7), 675-688.

Al-Azawi, R., Al-Faliti, F., \& Al-Blushi, M. (2016). Educational Gamification Vs. Game Based Learning: Comparative Study. International Journal of Innovation, Management and Technology, 7(4), 132-136.

Ali, A., \& Mahamod, Z. (2016). Pembangunan Dan Kebolehgunaan Modul Berasaskan Bermain Bagi Pembelajaran Kemahiran Bahasa Melayu Kanak-Kanak Prasekolah. Jurnal Pendidikan Bahasa Melayu, 6(1), 16-29.

Ali, A., \& Mahamod, Z. (2017). Analisis Keperluan Terhadap Pengguna Sasaran Modul Pendekatan Berasaskan Bermain bag Pengajaran dan Pembelajaran Kemahiran Bahasa Kanak-kanak Prasekolah. JuKu: Jurnal Kurikulum \& Pengajaran Asia Pasifik, 3(1), 1-8.

Alias, S.N., \& Ibrahim, F. (2017). Keberkesanan Permainan Pendidikan Terhadap Pembelajaran Hukum Newton The Effectiveness Of Educational Games On Newton's Laws Learning. Journal of Nusantara Studies (JONUS), 2(1), 71-85.

Alibeigynejad, M., \& Fahimniya, F. (2015). The Effect of Using Keyword Method on EFL Learners' Learning and Retrieving English Verb Types. Research in Applied Linguistics, 5, 35-42. 
Pembelajaran Berasaskan Permainan dalam Mata Pelajaran Sejarah Menggunakan Teknik Mnemonik

Received Date: 21 November 2019; Accepted Date: 29 January 2020

Arif, M., Risnasari, M. (2017). Penerapan Teknologi Game Berhitung Untuk Meningkatkan Kemampuan Matematika Pada Siswa Tingkat Sekolah Dasar. Edutic-Scientific Journal of Informatics Education, 3(1).

Ariffin, M.M., Oxley, A., \& Sulaiman, S. (2014). Evaluating Game-Based Learning Effectiveness in Higher Education. Procedia-Social and Behavioral Sciences, 123, 20-27.

Bakhsh, S.A. (2016). Using Games as a Tool in Teaching Vocabulary to Young Learners. English Language Teaching, 9(7), 120-128.

Davoudi, M., \& Yousefi, D. (2016). The Effect of Keyword Method on Vocabulary Retention of Senior High School EFL Learners in Iran. Journal of Education and Practice, 7(11), 106-113.

Derakhshan, A., \& Khatir, E.D. (2015). The Effects Of Using Games On English Vocabulary Learning. Journal of Applied Linguistics and Language Research, 2(3), 39-47.

Fasih, P., Izadpanah, S., \& Shahnavaz, A. (2018). The Effects of Mnemonic Vocabulary Instruction on Content Vocabulary Learning of Students. International Journal of Applied Linguistics \& English Literature, 7(3), 49-59.

Hendrowati, T.Y. (2015). Pembentukan Pengetahuan Lingkaran Melalui Pembelajaran Asimilasi dan Akomodasi Teori Konstruktivisme Piaget. JURNAL e-DuMath, 1(1).

Ibda, F. (2015). Perkembangan Kognitif: Teori Jean Piaget. Intelektualita, 3(1).

Köksal, O., \& Çekiç, A. (2014). The Effects Of The Mnemonic Keyword Method On 8th Graders' L2 Vocabulary Learning. Journal of International Scientific Publications, 12, 1030-1047.

Muhamad, N., Zakaria, M.A.Z.M., Salleh, S.M., \& Harun, J. (2018). Penggunaan Permainan Digital dalam Pembelajaran Bilik Darjah Bagi Meningkatkan Kreativiti Dalam Penyelesaian Masalah Matematik. Sains Humanika, 10(3-2).

Nadiyah, R.S., \& Faaizah, S. (2015). The Development Of Online Project Based Collaborative Learning Using ADDIE Model. Procedia-Social and Behavioral Sciences, 195, 1803-1812.

Ni, L.B., \& Hassan, N.A.B. (2019). The Use of Mnemonic and Mathematical Mnemonic Method in Improving Historical Understanding. World Academy of Science, Engineering and Technology International Journal of Educational and Pedagogical Sciences, 13(2), 93-97.

Nisa, K. (2019). Pembelajaran Geografi dan Alam Sekitar Menggunakan Permainan Digital GeoPlay. Tesis Phd. Tanjong Malim, UPSI.

Piribabadi, A., \& Rahmany, R. (2014). The Effect of the Keyword Method and Word-list Method Instruction on ESP Vocabulary Learning. Journal of Language Teaching \& Research, 5(5).

Putnam, A.L. (2015). Mnemonics In Education: Current Research and Applications. Translational Issues in Psychological Science, 1(2), 130.

Rawendy, D., Ying, Y., Arifin, Y., \& Rosalin, K. (2017). Design and Development Game Chinese Language Learning With Gamification And Using Mnemonic Method. Procedia Computer Science, 116, 61-67.

Siong, W.W., \& Osman, K. (2018). Pembelajaran Berasaskan Permainan Dalam Pendidikan STEM Dan Penguasaan Kemahiran Abad Ke-21. Politeknik \& Kolej Komuniti Journal of Social Sciences and Humanities, 3(1), 121-135.

Taheri, A.A., \& Davoudi, M. (2016). The Effect of The Keyword Method On Vocabulary Learning And Long-Term Retention. International Journal of Language and Linguistics, 3(1), 114-125.

Triana, M., Johar, R., \& Ansari, B.I. (2016, November). Students' Understanding in Learning Trigonometry Using Mnemonic Method. In Proceedings of English Education International Conference. Vol. 1, No. 2, 418-422.

Wiggins, B.E. (2016). An Overview and Study On The Use Of Games, Simulations, And Gamification In Higher Education. International Journal of Game-Based Learning (IJGBL), 6(1), 18-29.

Ying, Y., Rawendy, D., \& Arifin, Y. (2016, November). Game Educationfor Learning Chinese Language With Mnemonic Method. In 2016 International Conference on Information Management and Technology (ICIMTech) (pp. 171-175). IEEE. 